\title{
Effectiveness of a mobile smoking cessation service in reaching elderly smokers and predictors of quitting
}

\author{
Abu Saleh M Abdullah',2, Tai-Hing Lam*2, Steve KK Chan², \\ Gabriel M Leung'2, Iris Chi ${ }^{3}$, Winnie WN Ho ${ }^{2,5}$ and Sophia SC Chan ${ }^{4}$
}

Address: ${ }^{1}$ Department of International Health, Boston University School of Public Health, Boston, Massachusetts, USA, ${ }^{2}$ Department of Community Medicine, School of Public Health, Li Ka Shing Faculty of Medicine, The University of Hong Kong, Hong Kong, PR China, ${ }^{3}$ School of Social Work, University of Southern California, Los Angela, USA, ${ }^{4}$ Department of Nursing Studies, Li Ka Sing Faculty of Medicine, The University of Hong Kong, Hong Kong, PR China and ${ }^{5}$ Department of Social Work, Hong Kong Baptist University, Hong Kong, PR China

Email: Abu Saleh M Abdullah - asma@bu.edu; Tai-Hing Lam* - hrmrlth@hkucc.hku.hk; Steve KK Chan - schankk@hkucc.hku.hk; Gabriel M Leung - gmleung@hku.hk; Iris Chi - ichi@usc.edu; Winnie WN Ho - wwnho@HKUCC.HKU.HK;

Sophia SC Chan - nssophia@hkucc.hku.hk

* Corresponding author

Published: 6 October 2008

BMC Geriatrics 2008, 8:25 doi:10.1 |86/|47|-23/8-8-25
Received: 25 April 2008

Accepted: 6 October 2008

This article is available from: http://www.biomedcentral.com/I47I-23/8/8/25

(c) 2008 Abdullah et al; licensee BioMed Central Ltd.

This is an Open Access article distributed under the terms of the Creative Commons Attribution License (http://creativecommons.org/licenses/by/2.0), which permits unrestricted use, distribution, and reproduction in any medium, provided the original work is properly cited.

\begin{abstract}
Background: Different smoking cessation programmes have been developed in the last decade but utilization by the elderly is low. We evaluated a pilot mobile smoking cessation service for the Chinese elderly in Hong Kong and identified predictors of quitting.

Methods: The Mobile Smoking Cessation Programme (MSCP) targeted elderly smokers (aged 60 or above) and provided service in a place that was convenient to the elderly. Trained counsellors provided individual counselling and 4 week's free supply of nicotine replacement therapy (NRT). Follow up was arranged at I month by face-to-face and at 3 and 6 months by telephone plus urinary cotinine validation. A structured record sheet was used for data collection. The service was evaluated in terms of process, outcome and cost.
\end{abstract}

Results: 102 governmental and non-governmental social service units and private residential homes for the elderly participated in the MSCP. We held 90 health talks with 3266 elderly (I 140 smokers and 2126 non-smokers) attended. Of the II 40 smokers, 365 (32\%) received intensive smoking cessation service. By intention-to-treat, the validated 7 day point prevalence quit rate was $20.3 \%$ (95\% confidence interval: $16.2 \%-24.8 \%$ ). Smoking less than II cigarettes per day and being adherent to NRT for 4 weeks or more were significant predictors of quitting. The average cost per contact was US\$54 (smokers only); per smoker with counselling: US\$168; per self-reported quitter: US\$594; and per cotinine validated quitter: US\$827.

Conclusion: This mobile smoking cessation programme was acceptable to elderly Chinese smokers, with quit rate comparable to other comprehensive programmes in the West. A mobile clinic is a promising model to reach the elderly and probably other hard to reach smokers. 


\section{Background}

Cigarette smoking is the leading cause of premature mortality among older persons in Hong Kong [1,2] and elsewhere.[3] Many common diseases among older people are caused by tobacco use.[4,5] The World Bank has estimated that five hundred million people alive today will eventually be killed by tobacco.[6] Worldwide trends in mortality attributable to smoking will increase in both older men and women.[7]

The prevalence of cigarette smoking was $14 \%$ in Hong Kong people aged over 60 in the 1998 General Household Survey and there were a total of 129,600 older smokers at that time [8]. A higher prevalence of current smoking was reported in studies conducted among older people aged 60 and over by the Hong Kong Society for the Aged (19\%) [9] and by the University of Hong Kong (19\%) [10]. In Hong Kong, there has been a lack of smoking cessation services and there is no evidence whether such services could help older people to quit smoking. Nevertheless, about $15 \%$ of smokers aged 60 and older wanted to quit within the next 6 months [10] and evidence elsewhere shows that older smokers are more likely to be successful in quitting attempts than smokers aged 35-64.[11] This paper reports the acceptance and benefits of smoking cessation services among older smokers in Hong Kong.

Although a variety of smoking cessation programmes have been developed in the last decade, utilization by the elderly is low.[12] A frequently cited reason is inconvenience in reaching the services, [13] because the service locations are not near to their living environment. On the other hand, many elderly people live alone or in elderly homes and traveling to a smoking cessation clinic far away is not practicable. A more accessible service should encourage more people to utilize the service and benefit from it. Mobile clinical service was useful in reaching the hard to reach population in other settings.[14] However, we found no such reports in the literature that targeted elderly smokers with a mobile smoking cessation service. We examined the effectiveness of a mobile smoking cessation service in reaching elderly Chinese smokers in Hong Kong and identified predictors of quitting. We aimed to answer four specific questions: (1) Would Chinese elderly smokers participate in a mobile smoking cessation programme (MSCP)? (2) Is the programme effective in promoting smoking cessation among elderly Chinese smokers? (3) What are the predictors of quitting among the Chinese elderly? (4) What are the costs of the programme?

\section{Methods}

\section{Mobile smoking cessation programme (MSCP)}

The Departments of Community Medicine and Nursing Studies and School of Public Health of the University of Hong Kong with funding from the Elderly Commission,
Government of the Hong Kong Special Administration Region developed a Mobile Smoking Cessation Programme (MSCP) to reach elderly smokers (aged 60 or above). The MSCP started in November 2002 and continued till September 2004. The mobile team included a coordinator and 3 trained smoking cessation counsellors. These counsellors were registered nurses and had completed satisfactorily a smoking cessation counselling training programme with assessment by written and practical examinations. The mobile team was supported by a project director specialized in smoking cessation. The MSCP included health talks, assessment of clients' smoking status and nicotine dependence level, provision of individually tailored behavioural counselling, prescription of nicotine replacement therapy, NRT (patch only), and arrangements for follow up (telephone and on-site). We recommended subjects to use NRT for 8 weeks and gave out free supply for the first 4 weeks. We followed social cognitive theory (SCT) to design the intervention of the program. SCT explains why a behavior occurs positing that there is a three-way reciprocal interaction between the environment, the individual and a behavior [15]. The SCT has been successfully applied in several clinical and community based studies of smoking cessation $[16,17]$.

\section{Target population and recruitment}

The eligible subjects were current smokers who were attending 102 social service units or private residential homes (both Government and non-Government) throughout Hong Kong to receive health services or elderly care. All these service units were specialized in service provision for the elderly. We invited a social worker, if available, in each of these centres to act as our contact person. These social workers were trained by us on basic smoking cessation skills, the details of which were described elsewhere.[18,19] The respective social worker from each of these centres identified elderly smokers within their service areas and confirmed a date for the visit of the MSCP team. Elderly non-smokers and family members of elderly smokers who were interested to know about smoking and health issues were also encouraged to attend the health talks, but were not included in the analysis. Most of the private homes did not have social workers and some clients were referred by other staff members.

The health talks were organized in the premises of the social service centres. Each health talk continued for about an hour. The nurse counsellors from the mobile team delivered pre-designed talks (about 30 minutes) and discussed on different aspects of smoking cessation. The content included the harms of tobacco use (both active and passive smoking), benefits of quitting smoking and tips for quitting. Informal discussion, experience sharing, and a question and answer session were conducted during the second half of the talk, including brief information about the MSCP. 
After the health talks, all smokers were asked to enrol for an intensive smoking cessation service, including cognitive-behavoural stage matched counselling and use of NRT, which lasted for about half an hour, provision for free NRT supply for 4 weeks and follow up arrangements. Those who consented to participate were included in the programme (Figure 1). Ethical approval for this study was obtained from the Ethics Committee of the Faculty of Medicine, the University of Hong Kong.

\section{Data collection}

A structured questionnaire was used to collect data at baseline and at 1, 3 and 6 months. Details of the questionnaire were described elsewhere.[20,21] Briefly, the questionnaire included demographic information, smoking and quitting history, nicotine dependence level, and perceived motivation (self efficacy rating), confidence and difficulty of quitting smoking (perceived barriers). The client's satisfaction towards different aspects of MSCP was assessed at 3 month follow up, including counselling received in the centre and/or over the telephone, and follow up arrangements. Counsellors' satisfaction was assessed from the meeting notes, every 2 months. We asked the counsellors questions about the process of service delivery, operational guidelines, work load, availability of support and job satisfaction. Satisfaction was rated on a four-point scale (very satisfactory, satisfactory, unsatisfactory and very unsatisfactory).

\section{Follow up assessment}

Follow up assessment and relapse prevention counselling was carried out at 1 month post-counselling by face-toface and at 3 and 6 months by telephone for all who attended the MSCP. Both face-to-face and telephone follow up lasted for an average of 20 minutes. We also made a follow up call (lasting for 2-5 minutes) at 1 week to assess whether the elderly were having any problem with NRT use and encourage further use. The nurse counsellors carried out follow up interviews. At 6 months, those who stopped smoking (not smoking for 7 days or more preceding the follow up interview) were invited to attend the nearest social service unit for biochemical validation (by measuring urinary cotinine level). For those who could not attend for validation, our research assistant visited the subjects to collect urine samples.

\section{The evaluation}

The programme was evaluated in terms of process, outcome and cost. The process evaluation comprised documentation of comments or suggestions from the nurse counsellors and other members of the MSCP team, and satisfaction ratings of the subjects regarding counselling and follow up arrangements. The main outcome evaluation was based on the validated 7 day point prevalence quit rate at 6 months, and we also reported several other quitting outcomes as secondary outcomes. Other process outcomes included number of MSCP organized, number of elderly members attended the health talks, number of elderly smokers who had received intensive smoking cessation service (counselling and/or NRT) and contributions to smoking cessation research in Hong Kong and elsewhere. We calculated all the relevant costs (staff salary, stationery, NRT, travel for the mobile team, and urine cotinine tests) and divided the total costs by the total number of attendees/quitters and compared them with other relevant programmes.

\section{Data analysis}

Data were analyzed using SPSS for Windows, version 10.0. The baseline characteristics of clients were described. The prevalence of quitting in the MSCP was compared with those of studies elsewhere. The characteristics of quitters and non-quitters were compared by chi-square test. The variables which were significant in the bivariate analysis were tested by forward stepwise logistic regression modeling to identify predictors for quitting and to estimate adjusted odds ratios and 95\% confidence intervals $(\mathrm{CI})$.

Quitting smoking was defined as not smoking any cigarettes during the past 7 days at 6 month follow up as reported by the subjects and confirmed by urine cotinine validation ( 7 day point prevalence validated quit rate). All subjects who could not be contacted at 6 month follow up and those who failed the validation test (a urinary cotinine level > $100 \mathrm{ng} / \mathrm{ml}$ ) [22] were considered as smokers (i.e. had no change from baseline) based on intention-to-treat analysis (a conservative approach). As secondary outcomes, we also measured 7 day point prevalence quit rate at 6 months without validation (defined as not smoking during the 7 days preceding the 6 month follow up), 24 hour point prevalence quit rate at 6 months without validation (defined as not smoking during the 24 hours preceding the 6 month follow up), continuous abstinence rate (abstinence from tobacco smoking continuously for the whole period prior to the interview at 6 months) [23] and reduction in smoking rate (reduction of the amount smoked by at least $50 \%$ at 6 month follow up).[24]

\section{Results \\ Utilisation and process evaluation}

During the study period, we contacted a total of $1012 \mathrm{gov}-$ ernmental and non-governmental social service units and private residential homes for the elderly, and 102 participated in the MSCP. We organized 90 health talks (12 units did not require health talk but recruited smokers to receive our intensive counselling) with 1140 smokers attended. Of the 1140 smokers, $365(32 \%)$ agreed to receive our smoking cessation service. The demographic, lifestyle and quitting characteristics of these subjects are shown in Table 1. 


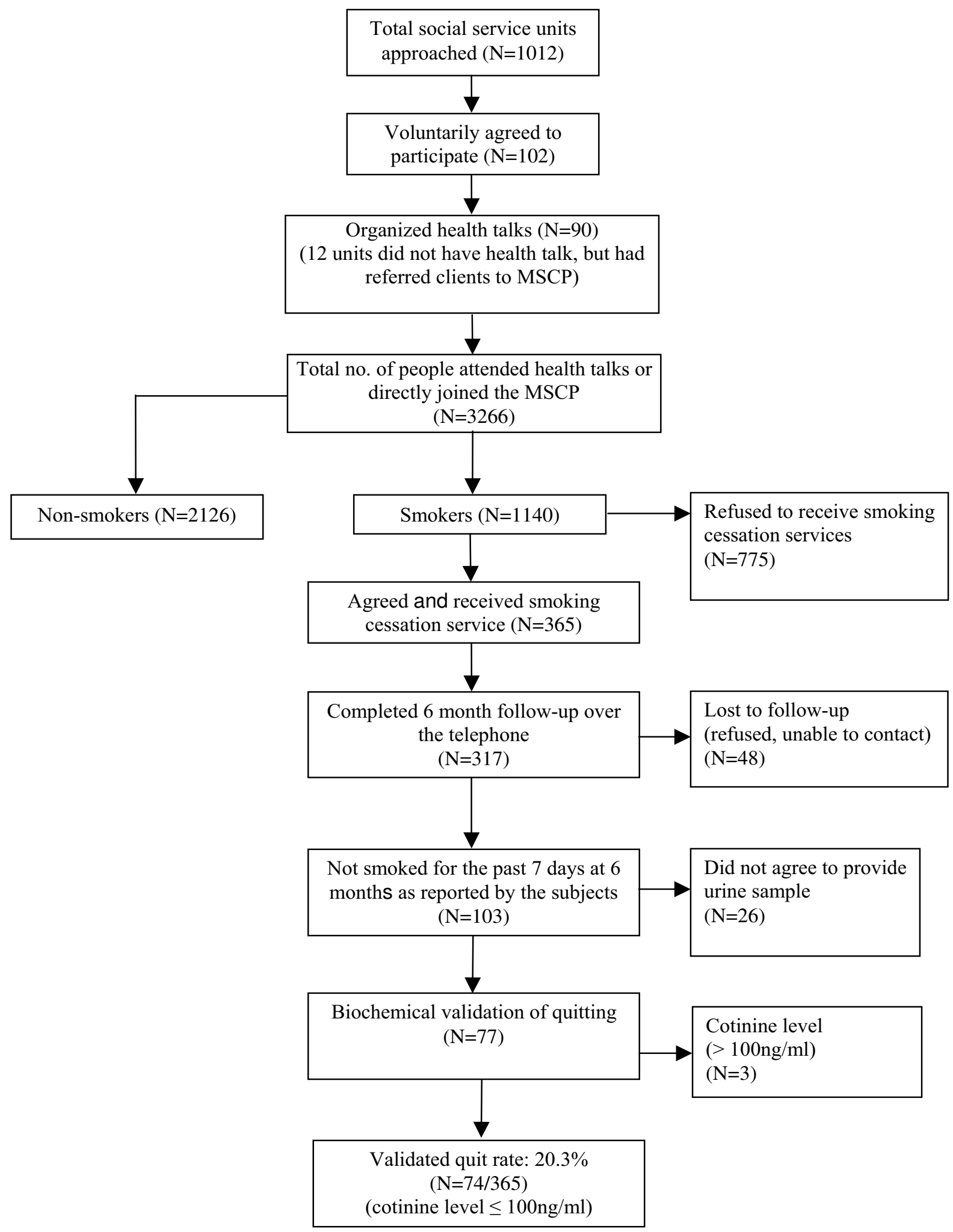

Figure I

Flow of subject recruitment in the Mobile Smoking Cessation Programme (MSCP). 


\section{Satisfaction}

More than $90 \%$ of the respondents were satisfied with the counselling service and follow up arrangements. Eighty five percent of the subjects would probably or definitely recommend this programme to other smokers. However, $80 \%$ of the subjects were asking for free full course of NRT, which was not possible as our funding could only support 4 week free supply.

Structured interview was also conducted with all the four counsellors and the coordinator, which showed that all the staff members were satisfied with the counselling process, supervisory support and workload. The main barrier was the travel time and communication difficulties with the elderly. Repeated reminders were necessary as many elderly often forgot about their follow up arrangements. No complaints about the programme and no other major difficulties were encountered.

\section{Outcome evaluation}

Primary outcome (urine cotinine validated quit rate)

At 6 month follow up, $48 / 365$ (13\%) subjects could not be reached (left Hong Kong, telephone number changed or refused to talk) and 103 subjects reported that they did not smoke in the 7 days preceding the 6 month follow up (Table 2). All the 103 self-reported quitters were invited for biochemical validation with urine cotinine test (Nicalert test) and 77 gave urine samples. Three of these had a cotinine level of $>100 \mathrm{ng} / \mathrm{ml}$ and were considered as smokers. By intention-to-treat analysis, the validated (cotinine level $=<100 \mathrm{ng} / \mathrm{ml}$ ) quit rate was $20.3 \%(74 /$ 365 ) (95\% confidence interval, CI: 16.2\%-24.8\%).

\section{Secondary outcomes}

At 6 month follow up, by intention-to-treat analysis, of the 365 subjects, $28.2 \%$ did not smoke any cigarettes during the 7 days prior to the interview ( 7 day point prevalence), 30.1\% did not smoke any cigarettes during the 24 hours prior to the interview ( 24 hour point prevalence), and $24.9 \%$ did not smoke any cigarettes during the six months prior to the interview ( 6 month continuous abstinence), and $25.8 \%$ reported that they did not quit but had reduced daily smoking by at least 50\% (reduction rate) (Table 2).

\section{Factors associated with quitting at 6 months}

With the inclusion of those who did not return for followup as non-quitters, we carried out bi-variate analysis of all the eighteen variables in Table 1 to identify factors associated with quitting. Nine factors were significantly associated with quitting: smoking less than 11 cigarettes per day, having made one or more serious quitting attempts in the past, being moderately or mildly dependent on nicotine, quitting for at least a day in the last quitting attempt, using NRT for at least a day in the present quitting attempt, being adherent to NRT use for 4 weeks or
Table I: Demographic, lifestyle, smoking and quitting related factors of 365 smokers to the mobile smoking cessation programme (MSCP) participants $(n=365)$

\section{C}

Demographics:
Gender
Male
Female

Occupational status

Retired

Unemployed

Employed

Homemakers

Age

60-69

$70-79$

80 or above

Educational attainment

No formal education $\quad 39$

Primary school 46

$\begin{array}{ll}\text { Secondary or above } & 15\end{array}$

Marital Status

Single

Married

Divorced, separated and widowed

21

Tobacco use related:

Daily cigarette consumption

$\leq 10$

$>10$

Age started smoking

Under 20

20 or above

Nicotine Dependency level a

Mild

Moderate

65

Severe

Number of other smokers in household

Nil

I or more

Smoking status of spouse

No spouse/spouse not smoker $\quad 90$

Spouse is smoker

Quitting History:

Number of previous quitting attempt(s) Nil

I attempt or more

Length of abstinence in the last quitting attempt

Less than a day or not at all

$>=$ I day

NRT related:

Use of NRT for at least I dayb

No

23

Yes

Adherence to use NRT for 4 weeks or more ${ }^{b, c}$

No

Yes

Other factors:

Perceived importance on quitting (mean score $=73)^{d}$ Less important $(<$ mean)

More important $(>=$ mean)

Perceived difficulties on quitting (mean score $=55)^{\mathrm{e}}$ Less difficult $(<$ mean $)$ 
more, perceiving more importance and confidence on quitting, and having an exhaled carbon monoxide level of below the mean $(<10 \mathrm{ppm})$ at the first visit. Stepwise logistic regression modelling on these nine factors showed that smoking less than 11 cigarettes per day and being adherent to NRT use for 4 weeks or more were the two significant independent predictors of quitting (Table $3)$.

\section{Costs of the MSCP}

The cost of the MSCP included mainly operation cost (staff salary and stationery), cost of equipment and NRT and travel cost for the mobile team. Some hidden costs such as time spent by the programme director and other members of the project team (who were involved mainly in the planning, monitoring, evaluation and research), and client costs (travel time, travel cost, cost to other family members) were not included. The total expenditure for the operation of MSCP was US\$ 61,162 (Table 4). The MSCP had 1140 smoker subjects for health talks and 365 smokers for smoking cessation service. At 6 month follow up, 103 smokers did not smoke any cigarettes during the past 7 days. 74/77 of the self-reported quitters who had cotinine validation were confirmed as quitters. Therefore, the cost per contact was US $\$ 53.65$ (smokers only); cost per smoker with counselling was US $\$ 167.57$; and cost per self-reported quitter was US $\$ 593.81$ and per cotinine validated quitter, US $\$ 826.54$.

\section{Discussion}

Our experience and findings from the mobile smoking cessation programme (MSCP) suggest feasibility and acceptance of this outreach programme among the Chinese elderly. Although the project was not designed as a controlled experiment, the results suggest that mobile smoking cessation programmes can be effective for the hard to reach population such as the elderly, provided that the needs and difficulties of the targeted population are addressed. While a community-based study in the United States reported that smokers aged 65 and older were least likely to use a smoking cessation programme, [8] our mobile service was reasonably accepted as reflected from clients' participation and enthusiasm. It was convenient for many elderly clients who could not travel to receive services far away. Few community smoking cessation projects used cotinine validation for evaluation of quitting outcomes. Our study has the strengths in the use of cotinine validation and the high percentage (75\%) of acceptance of the validation. It is worth mentioning that our cessation service was not able reach all the elderly smokers in the 102 participating social service units. Although we trained social workers in each of these units to refer smokers to our program, we did not conduct any baseline survey of all the residence in the studies social service units nor did record data about what pro-
Table I: Demographic, lifestyle, smoking and quitting related factors of 365 smokers to the mobile smoking cessation programme (MSCP) participants $(n=365)$ (Continued)

\begin{tabular}{ll}
\hline More difficult $(>=$ mean) & 47 \\
Perceived confidence on quitting (mean score $=67)^{f}$ & \\
Less confident $(<$ mean) & 42 \\
More confident $(>=$ mean) & 58 \\
Alcohol consumptiong & 18 \\
Regular user and occasional users & 82 \\
Never or rarely drink & \\
\hline
\end{tabular}

Note: Total percentage may be more or less than 100 due to rounding of the figures.

a Nicotine dependency level was measured by Fagerstrom scale, then further divided into 3 levels: low (score 0-3), moderate (score 4-8) and severe (score 6-10).; $\mathrm{n}=354,11$ missing.

bIncluded only those who were given NRT $(n=255)$.

cSubjects who reported using nicotine replacement therapy (NRT) for at least 4 weeks during the 3 month follow up was defined as adherent to NRT use.

dTotal $\mathrm{n}=352,13$ missing

eTotal $n=356,9$ missing

fTotal $\mathrm{n}=355,10$ missing

gTotal $\mathrm{n}=345,20$ missing

portion of the smokers actually attended the program. However, based on our exploratory estimate, we assume that our program reached at least $70 \%$ of the smoker population in these social service units.

Our service (individual counselling and 4 week free supply of NRT) resulted in a self-reported 6-month point prevalence quit rate (by intention-to-treat) of $28 \%$, which was comparable with the one year point prevalence selfreported quit rate $(27 \%)$ among Chinese adult smokers who attended the Hong Kong Smoking Cessation Health Centre, [25] and higher than the 6 month point prevalence self-reported quit rate (14.4\%) in clinic based smoking cessation services in New Zealand [26] and the United States (22\%).[27] Our quit rate was also comparable to the 7-day point prevalence self-reported quit rate (29\%) among American elderly (aged 65 to 74 years) who also used nicotine patch for an average of 5 weeks.[28] While our quit rates seems better than the above studies abroad [26-28], few clarifications worth noting. Our subject included a higher proportion $(70 \%)$ of those who were light smokers (smoked less than 10 cigarettes daily), however, based on our review of these studies $[26,27]$ papers, a higher proportion of subjects in other studies [26-28] were moderate or heavy smokers. The average daily consumption of our subject was 10 cigarettes per day compared to the mean number of 25.4 cigarettes per day among American smokers [27] and a median of 20 (range 1-85) among smoker in New Zealand [26].

The cost per self-reported quitter (US $\$ 458$, excluding cost for NRT) was $35 \%$ higher than that in the Hong Kong Smoking Cessation Health Centre, which was the first such clinic in Hong Kong (US\$339, excluding cost for NRT).[22] The higher cost was mainly due to the mobile 
Table 2: Quitting outcome of 365 smokers in the MSCP at 6 month follow up, by intention to treat

\begin{tabular}{lll}
\hline Quit rates & $\mathbf{N}$ & \% (95\% confidence interval) \\
\hline $\begin{array}{l}\text { Primary outcome: } \\
\text { Biochemically (urine cotinine) validated quit rate }\end{array}$ & 74 & $20.3(16.2-24.8)$ \\
\hline Secondary outcomes (self-reported) & & \\
7 day point prevalence quit rate & 103 & $28.2(23.6-32.8)$ \\
24 hours point prevalence quit rate & 110 & $30.1(25.4-34.8)$ \\
Continuous abstinence quit rate & 91 & $24.9(20.5-29.4)$ \\
Had not quit but had reduced smoking by at least 50\% from the baseline level & 94 & $25.8(21.3-30.2)$ \\
\hline
\end{tabular}

nature of the service, longer duration of counselling needed for elderly clients, and the additional costs for cotinine validation.

We found that being a light smoker (smoking less than 11 cigarettes per day) and using NRT for four weeks or more were significant independent predictors of quitting. This suggests that heavy smokers might need to be targeted with more intensive programmes.[29] Efforts to increase NRT adherence are also needed to improve quit rates. [20] Provision of free NRT supply for a longer duration (full course, 8 weeks) is suggested for those who want to use but cannot afford.

A major limitation of the study is the lack of a control group to compare the elderly who participated in our MSCP with those who did not. However, our validated quit rate of $20.3 \%$ is about two times the natural selfreported quit rate $(10.0 \%)$ among the elderly aged 65 or above in the US general population.[30] Moreover, participation in the study was voluntary and this might have resulted in the recruitment of more motivated smokers from the general population. On the other hand, motivation of clients to a mobile service would be lower than that among those who travel to a clinic further away. Some of our smokers could have attended the service due to the pressure and/or encouragement from other family members or social workers from the social service units, and the prohibition of smoking inside most units. It is also possible that free counselling service and offer of 4week's supply of NRT free of charge encouraged many smokers to attend the program.

This study has important public health implications. First, to the best of our knowledge, this is the first study to report promotion of smoking cessation programme through mobile service targetting the elderly smokers, and our experiences and results should be important for other smoking cessation service providers. Second, the low cost of the programme suggests that a mobile service could be promoted to attract more smokers in addition to the elderly. A timetable convenient to the target clients is needed and should be publicized through the health care facilities, elderly homes and other health centres. Health care and social service providers could be motivated to identify older smokers and, if no smoking cessation services are provided in their premises, could refer them to the appropriate mobile service scheduled nearer to their residents or clients. Mass media promotional activities would increase the coverage but the cost would be high and local publicity should be more affordable. The setting up of a smoking cessation service can provide a golden opportunity for publicity. For example, we held two exhibitions, which attracted about 800 people to visit our booths and collect self-help materials. Integration of the smoking cessation service with other existing mobile service (if any) can reach more clients with shared costs. Finally, it would be useful to test the effectiveness and cost effectiveness of mobile smoking cessation service for other vulnerable population groups (such as pregnant women and young people).

\section{Conclusion}

We conclude that a mobile smoking cessation program is a feasible approach to reach elderly smokers. The quit rate is comparable to other comprehensive programs in the West. We identified several predictors of quitting smoking through the mobile program which could guide the future service provision. A mobile clinic is a promising model to reach the elderly and probably other hard to reach smokers.

Table 3: Final logistic regression (forward stepwise) model to predict successful quitting at 6 month follow up

\begin{tabular}{lll}
\hline Independent variables & OR (95\% Cl) & P value \\
\hline Smoking less than II cigarettes per day & $2.63(1.37-5.06)$ & $<0.01$ \\
Adhered to NRT use for 4 weeks or more & $3.57(1.95-6.55)$ & $<0.001$ \\
\hline
\end{tabular}

Note: $\mathrm{OR}=$ adjusted odds ratio; $\mathrm{Cl}=$ Confidence interval 
Table 4: Costs for the Mobile Smoking Cessation Programme (MSCP)

\begin{tabular}{|c|c|}
\hline Costs & HK\$ \\
\hline Fixed capital costs & Not costed \\
\hline Stationary and equipment & 1,220 \\
\hline \multicolumn{2}{|l|}{ MSCP service costs } \\
\hline Salary of part-time smoking cessation counsellors & 328,569 \\
\hline Salary of other part-time supporting staff & $|8,67|$ \\
\hline \multicolumn{2}{|l|}{ NRT costs } \\
\hline Costs for 4 week free supply ( $50 \%$ discounted price) & 109,223 \\
\hline \multicolumn{2}{|l|}{ Biochemical validation costs } \\
\hline Cost for urine cotinine test & 7,294 \\
\hline \multicolumn{2}{|l|}{ General expenses } \\
\hline Transportation & 8,622 \\
\hline Photocopies & 3,465 \\
\hline Hidden cost (Time spent by the programme director and other members of the project team) & Not costed \\
\hline Total cost (in HK\$) & 477,064 \\
\hline Total cost (in US\$) & $\begin{array}{c}\mathbf{6 1 , 1 6 2} \\
\text { (US\$47,159 excluding NRT costs) }\end{array}$ \\
\hline
\end{tabular}

Note: US\$I = HK\$7.8

Cost per smoker contact $=$ US $\$ 611$ 162/II $40=$ US $\$ 53.65$

Cost per subject with intensive counselling $=$ US\$61162/365 = US\$167.57

Cost per successful self-reported quitter (intention to quit) $=$ US $\$ 61162 / 103=$ US $\$ 593.81$ (US $\$ 457.82$, excluding NRT costs)

Cost per validated quitter (intention to quit) $=$ US $\$ 61162 / 74=$ US $\$ 826.54$ (US\$637.18, excluding NRT costs)

\section{Competing interests}

The authors declare that they have no competing interests.

\section{Authors' contributions}

ASMA and THL originated the study, developed study protocol and supervised all aspects of its implementation. ASMA performed data analysis and drafted the manuscript. SKC and WNH assisted in data collection and in the analysis. THL provided in-depth comments in the earlier draft of the manuscript. GML, IC and SCC contributed to the interpretation of data and revising the final draft of the manuscript. All authors reviewed drafts of the manuscript and approved the version to be published.

\section{Acknowledgements}

We thank Pfizer Consumer Health (Hong Kong) for providing NRT supplies with a $50 \%$ discount rate. However, Pfizer played no role in the results/data analysis/preparation or approval of the manuscript. We also thank the social service units for the elderly for their logistic support. The study was funded by the Elderly Commission Community Partnership Scheme of the Government of the Hong Kong SAR (Ref no. 0I-07I).

\section{References}

I. Lam TH, Ho SY, Hedley AJ, Mak KH, Peto R: Mortality and smoking in Hong Kong: case-control study of all adult deaths in 1998. Br Med J 200I, 323:36I-2.

2. Lam TH, Li ZB, Ho SY, Chan WM, Ho KS, Tham MK, Cowling B], Schooling CM, Leung GM: Smoking, quitting and mortality in an elderly cohort of $\mathbf{5 6 0 0 0}$ Hong Kong Chinese. Tob Control 2007. 16:182-9.

3. Janssen F, Kunst AE: The Netherlands Epidemiology and Demography Compression of Morbidity research group. Cohort patterns in mortality trends among the elderly in seven European countries, 1950-99. Int J Epidemiol 2005, 34(5): I | 49-59.

4. LaCroix AZ, Lanag J, Scherr P, Wallace RB, Cornoni-Huntley J, Berkman L, Curb JD, Evans D, Hennekens CH: Smoking and mortality among older men and women in three communities. $N$ Engl J Med 1991, 324(23): 1619-1625.

5. Panginini-Hill A, Hsu G: Smoking and mortality among residents of a California retirement community. Am J Public Health 1994, 84:992-5.

6. World Bank: Curbing the epidemic: Government and the Economic of Tobacco Control Washington DC: The World Bank; 1999.

7. Peto R, Lopez AD, Borchan J, Thun M, Heath C Jr, Doll R: Mortality from smoking worldwide. $\mathrm{Br}$ Med J 1996, 52:I2-2I.

8. Census and Statistics Department, Hong Kong Government: Special Topics Report No. 20. General Household Survey 1998. Hong Kong: Government printer; 1998.

9. Leung EM, Lo MB: Social and health status of elderly people in Hong Kong. In The Health of the Elderly in Hong Kong Edited by: Lam SK. Hong Kong: Hong Kong University Press; 1997:43-6I.

10. Lam TH, Chan B, Ho SY, Chan SK: Report on Healthy Living Survey 1999. 1999 [http://www.info.gov.hk/gia/general/200004/27/ 0427III.htm]. Department of Community Medicine, The University of Hong Kong (funded by the Hong Kong Department of Health)

II. Hatziandreu RJ, Pierce JP, Letkopoulou M: Quitting smoking in the United States in 1986. J Natl Cancer Inst 1990, 82: 1402-6.

12. Brown DW, Croft JB, Schenck AP, Malarcher AM, Giles WH, Simpson RJ Jr: Inpatient smoking-cessation counseling and allcause mortality among the elderly. Am J Prev Med 2004, 26: $112-8$.

13. Abdullah AS, Simon JL: Health promotion in older adults: evidence based smoking cessation programmes for use in primary care settings. Geriatrics 2006, 61 1:30-4. 
14. Bandura A: Social Learning Theory. Englewood Cliffs, NJ: Prentice Hall; 1997.

15. Miller NH, Smith PK, BeBusk RF, Sobel DS, Taylor DB: Smoking cessation in hospitalized patients. Results of a randomized trial. Arch Intern Med 1997, 157:409-15.

16. Zheng $\mathrm{P}$, Guo $\mathrm{F}$, Chen $\mathrm{Y}, \mathrm{Fu} \mathrm{Y}, \mathrm{Fu} \mathrm{H}$ : A randomized controlled trial of group intervention based on social cognitive theory for smoking cessation in China. J of Epidemiology 2007, I7(5): I47-155.

17. Jin AJ, Martin D, Maberley D, Dawson KG, Seccombe DW, Beattie ]: Evaluation of a mobile diabetes care telemedicine clinic serving Aboriginal communities in Northern British Columbia, Canada. Int J Circumpolar Health 2004, 63:124-8.

18. Johnston JM, Chan SSC, Chan SK, Chan SK, Woo PP, Chi I, Lam TH: Training nurses and social workers in smoking cessation counseling: a population needs assessment in Hong Kong. Prev Med 2005, 40:389-406.

19. Leung GM, Chan SSC, Johnston JM, Chan SK: Effectiveness of an elderly smoking cessation counseling training programme for social workers: A longitudinal study. Chest 2007 |3 I: I | 57-65.

20. Lam TH, Abdullah AS, Chan SSC, Hedley AJ: Adherence versus quitting smoking: predictors among Chinese smokers. Psychopharmacology 2005, 177:400-8.

21. Abdullah AS, Lam TH, Chan SSC, Hedley AJ: Which smokers use the smoking cessation Quitline in Hong Kong and how effective is the Quitline? Tob Control 2004, 13:4|5-21.

22. Gariti P, Rosenthal DI, Lindell K, Hansen-Flaschen J, Shrager J, Lipkin C, Alterman Al, Kaiser LR: Validating a dipstick method for detecting recent smoking. Cancer Epidemiol Biomarkers Prev 2002, I I: I I23-5.

23. Platt S, Tannahill A, Watson J, Fraser E: Effectiveness of antismoking telephone helpline: follow up survey. $\mathrm{Br}$ Med J 1997, 3i 4: |37|-5.

24. Hurt RD, Croghan GA, Wolter TD, Croghan IT, Offord KP, Williams GM, Djordjevic MV, Richie JP Jr, Jeffrey AM: Does smoking reduction result in reduction of biomarkers associated with harm? A pilot study using a nicotine inhaler. Nicotine Tob Res 2000, 2:327-36.

25. Abdullah AS, Hedley AJ, Chan SSC, Lam H: Establishment and evaluation of a smoking cessation clinic in Hong Kong: a model for the future service provider. J Public Health Med 2004, 26:239-44.

26. Town GI, Fraser P, Graham S, McSweeney W, Brockway K, Kirk R: Establishment of a smoking cessation programme in primary and secondary care in Canterbury. N Z Med J 2000, I I 3:1 1 7-9.

27. Croghan IT, Offord KP, Evans RW, Schmidt S, Gomez-Dahl LC Schroeder DR, Patten CA, Hurt RD: Cost-effectiveness of treating nicotine dependence: the Mayo Clinic experience. Mayo Clin Proc 1997, 72:917-24.

28. Orleans CT, Resch N, Noll E, Keintz MK, Rimer BK, Brown TV, Snedden TM: Use of transdermal nicotine in a state-level prescription plan for the elderly. A first look at 'real-world' patch users. JAMA 1994, 27I:60I-7.

29. Gourlay SG, Benowitz NL: The benefits of stopping smoking and the role of nicotine replacement therapy in older patients. Drugs Aging 1996, 9(I):8-23.

30. Salive ME, Cornoni-Huntley J, LaCroix AZ, Ostfeld AM, Wallace RB, Hennekens $\mathrm{CH}$ : Predictors of smoking cessation and relapse in older adults. Am J Public Health 1992, 82: I268-7I.

\section{Pre-publication history}

The pre-publication history for this paper can be accessed here:

http://www.biomedcentral.com/1471-2318/8/25/prepub http://www.biomedcentral.com/1471-2318/8/25 